

\title{
Microalgae starch-based bioplastics: Screening of ten strains and plasticization of unfractionated microalgae by extrusion
}

Charlie Mathiot, Pauline Ponge, Benjamin Gallard, Jean-Francois Sassi, Florian Delrue, Nicolas Le Moigne

\section{To cite this version:}

Charlie Mathiot, Pauline Ponge, Benjamin Gallard, Jean-Francois Sassi, Florian Delrue, et al.. Microalgae starch-based bioplastics: Screening of ten strains and plasticization of unfractionated microalgae by extrusion. Carbohydrate Polymers, 2019, 208, pp.142-151. 10.1016/j.carbpol.2018.12.057 . hal-02425058

\section{HAL Id: hal-02425058 \\ https://hal.science/hal-02425058}

Submitted on 26 Feb 2020

HAL is a multi-disciplinary open access archive for the deposit and dissemination of scientific research documents, whether they are published or not. The documents may come from teaching and research institutions in France or abroad, or from public or private research centers.
L'archive ouverte pluridisciplinaire HAL, est destinée au dépôt et à la diffusion de documents scientifiques de niveau recherche, publiés ou non, émanant des établissements d'enseignement et de recherche français ou étrangers, des laboratoires publics ou privés. 


\title{
Microalgae starch-based bioplastics: Screening of ten strains and plasticization of unfractionated microalgae by extrusion
}

\author{
Charlie Mathiot $^{\mathrm{a}}$, Pauline Ponge ${ }^{\mathrm{b}}$, Benjamin Gallard ${ }^{\mathrm{b}}$, Jean-François Sassi ${ }^{\mathrm{a}}$, Florian Delrue ${ }^{\mathrm{a}, *}$, \\ Nicolas Le Moigne ${ }^{\mathrm{b}, *, 1}$
}

${ }^{\text {a }}$ CEA Cadarache, Groupe Biomasse 3G, Saint-Paul-lez-Durance F-13108, France

${ }^{\mathrm{b}}$ Centre des Matériaux des Mines d'Alès (C2MA), IMT Mines Alès, Université de Montpellier, 6 avenue de Clavières, 30319 Alès Cedex, France

\begin{abstract}
A B S T R A C T
Microalgae were considered in this work as a new resource for developing starch-based bioplastics. Ten green microalgae strains were screened at lab-scale for their ability to produce starch. A long run $(800 \mathrm{~h})$ two-stage accumulation strategy was designed with successive cultivation in sulfur-replete, then sulfur-depleted medium in autotrophic conditions. Starch content was assessed on cell lysate by enzymatic digestion of extracted starch into glucose. Chlamydomonas reinhardtii 11-32A strain was selected as it displayed a maximum starch-to-biomass ratio of $49 \% \mathrm{w} / \mathrm{w}, 460 \mathrm{~h}$ after being switched to a sulfur-deprived medium. Small-scale pilot production (30 L tubular photobioreactor) with $C$. reinhardtii 11-32A yielded sufficient biomass quantity to investigate its direct plasticization with glycerol in a twin-screw extruder. Microstructural characterization confirmed the ability for starch-enriched microalgae to be homogeneously plasticized, and hence the possibility to use microalgae as a new platform for the development of bioplastics.
\end{abstract}

Keywords:

Microalgae

Bioplastics

Starch

Plasticization

Extrusion

\section{Introduction}

Along with the growing climate awareness and environmental interest of consumers, and now that environmental responsibility has risen as a recurring argument in marketing strategies (Nyilasy, Gangadharbatla, \& Paladino, 2014), companies become particularly keen on embracing new greener options for the production of chemicals and polymer materials. Indeed, it appears that durable and long-lasting plastics are not always appropriate for short-term applications (packaging, agriculture, hygiene, biomedical, leisure, etc.), for which biodegradation or bioassimilation would be key additional properties (Halley \& Dorgan, 2011; Ren, 2003). In this regard, since the beginning of the $90 \mathrm{~s}$, genuine bio-based and/or biodegradable plastic materials were developed such as biopolyesters (poly(lactic acid) PLA, poly(hydroxyalkanoates) PHAs, poly(butylene succinate) PBS, most notably) and thermoplastic starches (TPS).

Glucose-based polymers such as starch are the most widespread storage forms of carbon and energy in the biosphere (Blankenship, 1992). In that respect, starch associates the advantages of being cheap, abundant and biodegradable, which makes TPS an interesting alternative to petroleum-based plastics for the crafting of a whole range of bioplastic materials (Swanson, Shogren, Fanta, \& Imam, 1993; Ma \& Yu, 2004). However, the environmental virtue of its production is increasingly questioned, as current starch production systems rely on the same crucial biomass that staple food markets (cereals, corn, potatoes,...) (Mülhaupt, 2013).

Microalgae are an extremely diverse type of unicellular organisms able to carry out the biological fixation of mineral carbon through photosynthesis; their energy storage is primarily ensured by the intracellular production of branched polysaccharides, under the form of starch granules in green algae (Ball, Dirick, Decq, Martiat, \& Matagne, 1990; Jaiswal \& Chibbar, 2017). These unicellular plants associate the advantages of very high growth and productivity rates both higher than most terrestrial plants. Furthermore, production technologies allow it to be grown on non-arable lands; thus limiting the pressure on feed and food production systems and global markets (Wijffels, Kruse, \& Hellingwerf, 2013). Depending on strains, microalgae can be cultivated on saline, fresh or brackish water and could potentially be coupled with urban and agricultural wastewater treatment (Delrue, Álvarez-Díaz, Fon-Sing, Fleury, \& Sassi, 2016). They are abundant in ecosystems: estimations range between 200,000 and several millions species, compared to 250,000 species for higher plants (Norton, Melkonian, \&

\footnotetext{
* Corresponding authors.

E-mail addresses: florian.delrue@cea.fr (F. Delrue), nicolas.le-moigne@mines-ales.fr (N. Le Moigne).

${ }^{1}$ C2MA is member of the European Polysaccharide Network of Excellence (EPNOE), http://www.epnoe.eu.
} 


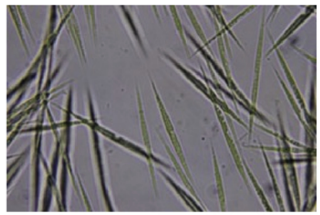

A. falcatus (x60, phase contrast)

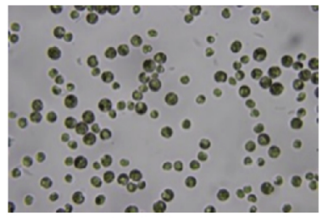

C. reinhardtii

1132A (x20, phase contrast)
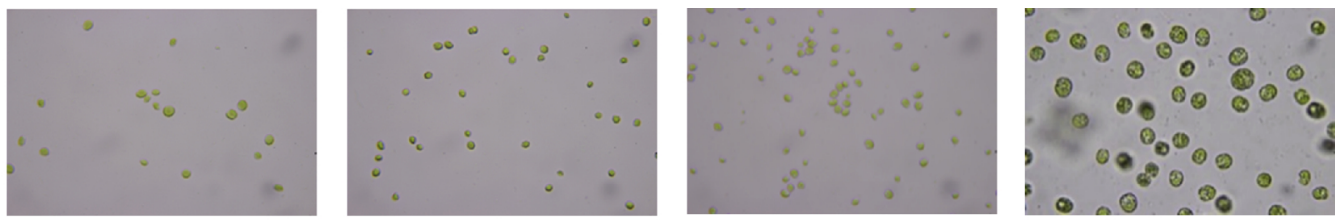

C. sorokiniana

C. variabilis (x20)

C. vulgaris ( $\mathrm{x} 20)$

\section{C. reinhardtii \\ DW15 (x60, phase \\ contrast)}


P. kessleri (x20,

Lugol staining)

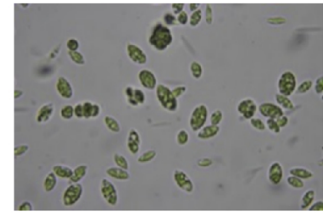

S. obliquus (x60, phase contrast)

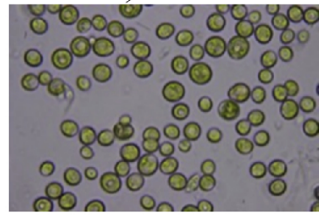

S. sp. (x60, phase

contrast)

Fig. 1. Microphotographs of the ten microalgal strains.

Andersen, 1996). They also present an extreme diversity of cell structures and physiologies (Singh \& Saxena, 2015) which represents a generous matter with great screening potential for a long yet promising strain selection work. Microalgae are photoautotrophs (some species exclusively, and some mixotrophs can also grow heterotrophically on an organic carbon source). They use light as an energy source in the process of photosynthesis, which assimilates mineral carbon $\left(\mathrm{CO}_{2}\right)$ into glucose (Blankenship, 1992). This glucose can provide immediate energy for cellular maintenance (via glycolysis), or participate in the building of cell structural materials (cell growth) and storage compounds such as starch or triglycerides (Johnson \& Alric, 2013; Radakovits, Jinkerson, Darzins, \& Posewitz, 2010). Actually, thanks to their adaptation to an ever-changing environment, microalgae display an outstanding ability to perform spontaneous and significant physiological reorientations with changes in their cultivation conditions without any genetic engineering, in particular in their photosynthetic apparatus, carbon metabolism and intracellular architecture. Hence, when placed in stress conditions, various microalgae strains have been extensively reported to accumulate biopolymers such as polysaccharides including starch (Cheng, Labavitch, \& VanderGheynst, 2014; Yao, Ai, Cao, Xue, \& Zhang, 2012), lipids (Hu et al., 2008), proteins (Markou, Angelidaki, \& Georgakakis, 2012), pigments (Kobayashi, Kurimura, \& Tsuji, 1997) and other metabolites, yet with significant constraints on culture growth (Chen et al., 2011). In particular, macronutrients depletion in the culture medium (typically nitrogen, sulfur and phosphate) has been broadly reported as a major mean for the induction of biopolymer storage in microalgae (Ball et al., 1990; Jerez, Malapascua, Sergejevová, Figueroa, \& Masojídek, 2015; Li, Horsman, Wang, Wu, \& Lan, 2008; Vítová, Bišová, Kawano, \& Zachleder, 2015). Both the selection of suitable strains and the design of specific culture and stress induction protocols constitute crucial steps for the optimal biotechnological production of these molecules.

In this context, this study aims at defining the biotechnological and processing routes for the production of starch-based bioplastics from microalgae. By X-ray diffraction analysis of starch granules isolated from model green algae C. reinhardtii, Buléon et al. (1997) revealed their remarkable structural similarity with starch from cereal endosperms (both ' $\mathrm{A}$ ' type, as opposed to ' $\mathrm{B}$ ' and ' $\mathrm{C}$ ' types in peas and tubers), with a variable $15-30 \%$ ratio of linear amylose chains over branched amylopectin chains.

With the objective of keeping a strong tie with preexisting starch references and their thermoplastic processing, this study focuses on the accumulation of starch in green algae species. Ten microalgae strains were compared in their potential to produce starch. For that purpose, a long-run two-staged cultivation process, in sulfur-repleted, then sulfurdeprived conditions was performed (Brányiková et al., 2011). As evoked before, cell starvation through nitrogen limitation is often chosen as an efficient mean of increasing starch production (Dragone, Fernandes, Abreu, Vicente, \& Teixeira, 2011). Yet, it presents the main drawback (shared with phosphorus limitation) of seriously diminishing cell viability on a relatively short time interval, given its general impact on cell metabolism, and gamete differenciation (Schmollinger et al., 2014). Because Brányiková et al. (2011) targeted the achievement of the longest interval between attainment of maximum starch content and cell death (due to nutrient lack) as a major stake for large-scale production; we selected sulfur limitation as an appropriate compromise. The most promising species (in terms of final intracellular starch content) was then used to upscale the process in a $30 \mathrm{~L}$ tubular photobioreactor (PBR) for the production of sufficient biomass quantity to carry out plasticization experiments. Both starch-'accumulated' and 'non-accumulated' microalgal biomasses underwent a melt processing in a lab twin-screw extruder, with glycerol as a plasticizing agent. The plasticization capacity and the microstructure of the plasticized microalgae were analyzed by optical microscopy and Scanning Electron Microscopy (SEM) observations and Differential Scanning Calorimetry (DSC) experiments.

\section{Materials and methods}

\subsection{Microalgae strains and media}

Ten microalgal strains were used: Ankistrodesmus falcatus (NIES2195), Chlamydomonas reinhardtii (strains DW15 and 11-32A), Chlorella sorokiniana (NIES-2173), Chlorella variabilis (NC-64A), Chlorella vulgaris (NIES-227), Parachlorella kessleri (NIES-2152), Scenedesmus acutus (NIES-94), Scenedesmus obliquus (NIES-2280) and Scenedesmus sp. Fig. 1 shows microphotographs of the ten microalgal strains. The two Chlamydomonas strains were selected as most of the research available on microalgae starch has been done on Chlamydomonas. The other eight strains were chosen, as they are known to be robust and fast-growing microalgae.

They were maintained on agar plates $(2 \% \mathrm{w} / \mathrm{w}$ agar) with Trisacetate-phosphate (TAP) medium. TAP medium is composed of minimal medium (MM) with $0.1 \% \mathrm{v} / \mathrm{v}$ acetic acid. Minimal medium is composed of $\mathrm{NH} 4 \mathrm{Cl}, 7.5 \mathrm{mM}$; $\mathrm{CaCl} 2,0.39 \mathrm{mM}$; $\mathrm{MgSO} 4,0.41 \mathrm{mM}$; K2HPO4, $0.61 \mathrm{mM} \quad ; \quad \mathrm{KH} 2 \mathrm{PO} 4, \quad 0.39 \mathrm{mM} ; \quad 3$-( $N$-morpholino)- 
propanesulfonic acid (MOPS), $19.4 \mathrm{mM}$ (pH buffer) and trace elements as $1 \mathrm{~mL} / \mathrm{L}$ of the Hutner solution (Hutner, Provasoli, Schatz, \& Haskins, 1950). The $\mathrm{pH}$ was adjusted from 7.2 to 7.4 with $1 \mathrm{M} \mathrm{KOH}$ before being sterilized in an autoclave at $121^{\circ} \mathrm{C}$ for $20 \mathrm{~min}$.

Sulfur-depleted medium (MM-S) for starch accumulation was prepared substituting chemical species with osmotic equivalents, i.e. $\mathrm{MgCl} 2$ was used instead of $\mathrm{MgSO} 4$. A specific sulfate-free Hutner solution was used in which $\mathrm{CuCl} 2, \mathrm{FeCl} 2$ and $\mathrm{ZnCl} 2$ respectively replace $\mathrm{CuSO} 4, \mathrm{FeSO} 4$ and $\mathrm{ZnSO} 4$.

\subsection{Growth conditions}

Pre-cultures were grown in minimal medium (MM) from agar plates to adapt cells to autotrophy. Aliquots from the precultures were used as inocula (initial OD: 0,1) in $125 \mathrm{~mL}$ flasks in triplicate. Cells were grown in HT Multitron Pro incubators (Infors HT, Switzerland) at $25^{\circ} \mathrm{C}$, under an incident photosynthetic photon fluxd ensity ( PPFD) of $125 \mu \mathrm{molm}^{-1} \mathrm{~s}^{-1}$, in photoperiod of $18 \mathrm{~h}$ light: $6 \mathrm{~h}$ dark cycles. Agitation was kept at $125 \mathrm{rpm}$ and air was enriched with $1 \% \mathrm{CO}_{2}$. Medium switching (from sulfur-replete to sulfur-deplete media) and cell harvesting were performed by centrifugation for $7 \mathrm{~min}$ at $3000 \mathrm{rpm}$.

A $30 \mathrm{~L}$ tubular photobioreactor (PBR) designed by IGV-Gmbh (Germany) has also been used as a small-scale pilot, in a single batch. A 6-liters centrifuge (model Avanti J-26SXP, Beckman-Coulter, USA) was used for medium switching ( $7 \mathrm{~min}, 3000 \mathrm{rpm}$ ) and biomass harvesting (7 min, $8000 \mathrm{rpm})$. The harvested biomass was immediately freezedried (COSMOS lyophilizer, Cryotec, France).

\subsection{Culture parameters}

Cell growth was determined by optical density measurements at $880 \mathrm{~nm}$ with a UV-vis Epoch2 spectrophotometer (BioTek Instruments, USA), in 96-well plates.

Biomass production measurements involved filtering c ulture aliquots (5 or $10 \mathrm{~mL}$ ) on pre-weighted GF/C glass fiber fi lters (pores diameter of $1 \mu \mathrm{m}$ ). After careful rinsing with distilled water, the filters were placed overnight at $105^{\circ} \mathrm{C}$ in a dry oven. The dry cell weight (DCW), illustrating the biomass concentration in $\mathrm{g} / \mathrm{L}$, is given by the ratio between the weight difference between empty and dried filter, and the volume filtered. Biomass productivity was calculated using Eq. (1) with $\mathrm{X}_{\mathrm{t}}$ the biomass concentration in $\mathrm{g} / \mathrm{L}$ at a given growth time $\mathrm{t}$.

Biomass productivity $\left(\right.$ from $t_{1}$ to $\left.t_{2}\right)=\frac{X_{t_{2}}-X_{t_{1}}}{t_{2}-t_{1}}$

\subsection{Starch content analysis}

A starch-specific enzymatic protocol modified from Chochois et al. (2009) was used to precisely measure microalgae starch content. It was preferred to the Dubois method (Dubois, Gilles, Hamilton, Rebers, \& Smith, 1956) and to the sulfuric acid-anthrone method (Somani, Khanade, \& Sinha, 1987) as these methods are not specific and a broad range of carbohydrates can be hydrolyzed by the sulfuric acid.

The enzymatic protocol was initially designed for Chlamydomonas reinhardtii, a specific sonication step was added. Briefly, $2 \mathrm{~mL}$ daily samples were directly stored in tubes with screw caps at $-18^{\circ} \mathrm{C}$. They were thawed before undergoing 2 cycles of $3 \times 7 \mathrm{~s}$ sonication pulses in a lab-size sonicator VibraCell VCX 500, equipped with a 3-mm microprobe (Bioblock Scientific). Tubes were stored on ice in between sonication cycles to avoid polymers solubilization with rising temperature. They were then centrifuged $10 \mathrm{~min}$ at $10000 \mathrm{rpm}$, and the supernatant discarded. The pellet was resuspended in $1 \mathrm{~mL}$ methanol for lipids and pigments extraction, in order to maximize the access of the enzyme to cell residues. After a second centrifugation, the organic phase was discarded, and the pellet resolubilized in $400 \mu \mathrm{L}$ of de-ionized water, then autoclaved (dry-cycle: $20 \mathrm{~min}$ at $121^{\circ} \mathrm{C}$ ) to solubilize the polymers. Samples were then incubated overnight at $55^{\circ} \mathrm{C}$ with an amyloglucosidase $10 \mathrm{U} / \mathrm{mL}$ (Roche, Mannheim, Germany) to break down amylose and amylopectin polymers into glucose units. The glucose content in the hydrolysate was finally titrated with a Biochemistry Analyser 295OD (YSI Life Sciences, USA): a glucose oxidase catalyzes the oxidation of glucose residues into $\partial$-gluconolactone $+\mathrm{H}_{2} \mathrm{O}_{2}$. The spontaneous dismutation of $\mathrm{H}_{2} \mathrm{O}_{2}$ on a platinum electrode generates a microcurrent ( $60 \mathrm{nA}$ max) proportional to the glucose concentration released by the amyloglucosidase.

Starch being actually made of anhydroglucose units (AGU) (starch polymerisation eliminates one water molecule per glucose unit added), a reduction coefficient of 0.9 (equal to the ratio $\mathrm{MW}_{\mathrm{AGU}} / \mathrm{MW}_{\mathrm{Glu}}$, where $\mathrm{MW}_{\mathrm{AGU}}=162.14 \mathrm{~g} \mathrm{~mol}^{-1}$ and $\mathrm{MW}_{\mathrm{Glu}}=180.15 \mathrm{~g} \mathrm{~mol}^{-1}$ ) is applied to obtain the starch content equivalent in the extract.

\subsection{Osidic composition}

The osidic composition was performed by the CERMAV (Centre de Recherche sur les Macromolécules Végétales, Grenoble, France) according to the Kamerling et al. method (Kamerling, Gerwig, Vliegenthart, \& Clamp, 1975) modified by Montreuil et al. (1986). Briefly, samples underwent a methanol/hydrochloric acid saccharification at $110^{\circ} \mathrm{C}$ for $4 \mathrm{~h}$, releasing monosaccharides then converted to trimethylsilylated-methylglycosides. Three samples from the mix were then analyzed in a GC-FID system (GC-6850 Agilent, column type HP5MS) with hydrogen as carrier gas. Peaks from the chromatogram are automatically interpreted as mass ratio of individual monosaccharides on total biomass.

\subsection{Microalgae plasticization protocols}

Plasticization of microalgae in glycerol under static conditions (i.e. no shearing applied) was studied with an optical microscope in transmitted light (Laborlux 11 POL S, Leitz, Germany) equipped with a microscope heating stage (LTS420, Linkam, UK). Videos were recorded with a digital camera (Leica DFC 420, 5 megapixel CCD) piloted by the software Replay ${ }^{\circledR}$ (Microvision Instruments, France). Samples of 'accumulated' microalgae were placed under two glass plates in presence of large excess of glycerol. A heating cycle at $5{ }^{\circ} \mathrm{C} / \mathrm{min}$ was applied to the mixture up to $140^{\circ} \mathrm{C}$. Maize starch (Prolabo, France) was used as reference and analyzed in the same conditions.

Plasticization of microalgae in glycerol under shearing conditions was performed as follows: the 'non-accumulated' and 'accumulated' lyophilized biomass samples were left for soaking with $30 \% \mathrm{w} / \mathrm{w}$ glycerol at $4{ }^{\circ} \mathrm{C}$ the night before the plasticization assays. The mixture was evenly split in $15 \mathrm{~g}$ batches, sufficient to fill the mixing chamber of a twin-screw extruder (microcompounder model MC5, Xplore, Netherlands). Twin-screw extrusion is a classical thermoplastic-processing tool for mixing and/or plasticizing polymers and obtaining homogeneous blends. Microalgae/glycerol batches underwent direct plasticization at different temperatures $\left(100^{\circ} \mathrm{C}, 120^{\circ} \mathrm{C}\right.$ and $\left.150{ }^{\circ} \mathrm{C}\right)$ with a screw speed of $100 \mathrm{rpm}$ and a mixing time of $2 \mathrm{~min}$. The resulting extrudates were collected for each processing conditions.

\subsection{Microstructural and thermal characterization of plasticized microalgae}

Extrudates were optically characterized as such, and at the level of a fracture in their cross-section, using a binocular magnifier (WILD M8, Germany) interfaced with a computer. Scanning Electron Microscopy (SEM) observations of the extrudates cross-section were performed with a Quanta 200 FEG (FEI, Netherlands). Cryo-fractured samples in liquid nitrogen were sputter coated with carbon using a Carbon Evaporator Device CED030 (Balzers), and observed in the SEM chamber at an acceleration voltage of $3 \mathrm{KeV}$.

Glass transition temperatures $(\mathrm{Tg})$ of plasticized microalgae were determined by Differential Scanning Calorimetry (DSC) using a Pyris 
Diamond DSC thermal analysis system (Perkin Elmer) equipped with an Intracooler II. Samples of roughly $25 \mathrm{mg}$ were placed into aluminum pans. An empty aluminum pan was used as reference. Successive heating and cooling scans were performed using nitrogen as purging gas from $-50{ }^{\circ} \mathrm{C}$ to $150^{\circ} \mathrm{C}$ at a rate of $10^{\circ} \mathrm{C} / \mathrm{min}$, then from $150{ }^{\circ} \mathrm{C}$ to $-50{ }^{\circ} \mathrm{C}$ at a rate of $20{ }^{\circ} \mathrm{C} / \mathrm{min}$ and finally from $-50{ }^{\circ} \mathrm{C}$ to $150{ }^{\circ} \mathrm{C}$ at a rate of $10^{\circ} \mathrm{C} / \mathrm{min}$. Tg was defined as the temperature at the half-height of the heat capacity variation on the heating scans. Measurements were repeated in triplicate for each sample.

Thermogravimetric Analysis (TGA) was used to determine the water content in microalgae/glycerol systems after the extrusion process. Experiments were conducted under nitrogen atmosphere $(100 \mathrm{ml} / \mathrm{min})$. $20 \mathrm{mg}$ of each sample was heated from 30 to $900^{\circ} \mathrm{C}$ at $10^{\circ} \mathrm{C} / \mathrm{min}$. The moisture content was determined based on the mass loss between $30^{\circ} \mathrm{C}$ and $130^{\circ} \mathrm{C}$. Measurements were repeated in duplicate for each sample.

\section{Results}

\subsection{Microalgae strain comparison}

The ten microalgae strains were compared on a two-stage culture. During the first stage, the microalgae showed a steady growth (Fig. 2). C. vulgaris, P. kessleri, C. sorokiniana and $S$. acutus showed the best average biomass productivities during the $360 \mathrm{~h}$ of the first stage with $0.492,0.475,0.453$ and $0.434 \mathrm{~g} / \mathrm{L} / \mathrm{d}$ respectively. Both $C$. reinhardtii strains (DW15 and 11-32A) were the slowest-growing microalgae with average biomass productivity for this first stage of 0.190 and $0.218 \mathrm{~g} / \mathrm{L} /$ d, respectively.

Cells were harvested after $367 \mathrm{~h}$ of growth when exhibiting symptoms of a late exponential-like phase. The first $48 \mathrm{~h}$ after the switch to a fresh sulfur-deprived medium (MM-S) saw a significant OD take off in all strains. It is imputable to both the providing of nutrients (notably ammonium) that went limiting over the course of the 2-week primary growth phase, and the cell swelling in stress-conditions (illustrating reserve build-up), artificially increasing OD despite limited changes in cell numbers.

The ten strains displayed variable affections in their g rowth after the medium switch. On one hand, C. reinhardtii DW15, C. sorokiniana and C. variabilis seem to be particularly affected in their growth ability, basically stopping most cellular division within $48 \mathrm{~h}$. On the other hand, the lack of sulfur had minor effects on the growth of $P$. kessleri, $C$. vulgaris and Scenedesmus sp. with average biomass productivity for this second step of $0.189,0.237$ and $0.258 \mathrm{~g} / \mathrm{L} / \mathrm{d}$. All other strains underwent a growth impairment of variable intensity. Interestingly, in spite of a nearly 20-days sulfur deprivation, no strains showed signs of culture perishing, thanks to an intense cell metabolism oriented towards sulfur scavenging and recycling, already highlighted by GonzálezBallester et al. (2010).

Relative starch content of the biomass during the accumulation phase is reported on Fig. 3. The two $C$. reinhardtii strains stand out. $C$. reinhardtii 11-32A reveals an interesting steady increase pattern of longterm starch accumulation, up to $49 \%$ after 20 days of sulfur-deprivation, representing a concentration of $5.07 \mathrm{~g}$ of starch per liter of algae culture. C.reinhardtii DW15 displays a limited yet stable relative starch content around $15 \%$ about 5 days after the medium switch, shortly after reaching a peak at $25 \%$ directly upon medium switch.

Apart from both C. reinhardtii strains, most strains seem to respond rather poorly to sulfur depletion in terms of starch accumulation. These starch content numbers are significantly lower than those reported in literature, obtained with other cell disrupting techniques and starch determination methods. With the example of $C$. vulgaris, Brányiková et al. (2011) reported values reaching up to $60 \%$ of relative starch content in similar growth conditions (and sulfur-depletion). In the present study, the cell lysis method is probably not able to break the most robust cell walls like the one from the Chlorella genre. Indeed, the protocol hereby chosen was originally designed for $C$. reinhardtii, whose ratio cell volume/cell wall thickness (a key feature for ultrasonication efficiency) is larger, thus explaining the reported accumulation performance for these cell types. The poor response of smaller cell types as Chlorella strains are partly due to their thicker cell walls. Adding a sonication step to the protocol, with the idea of generalizing it to other cell types, did not sufficiently improve the lysis efficiency.

\section{2. $30 \mathrm{~L}$ pilot-scale culture}

Based on both growth performances and starch accumulation potential, $C$. reinhardtii $11-32 \mathrm{~A}$ appeared as a good compromise in the preliminary strain selection process. This strain was then chosen to inoculate a $30 \mathrm{~L}$ PBR for biomass production, and upscale the starch accumulation induction technique through sulfur depletion (Fig. 4). A maximum of biomass productivity of $0.312 \mathrm{~g} / \mathrm{L} / \mathrm{d}$ was observed after $200 \mathrm{~h}$ of operation, partly attributable to the apparition of a contamination for the 'accumulated' biomass. Indeed, observations under optical microscope of the 'accumulated' biomass saw the gradual

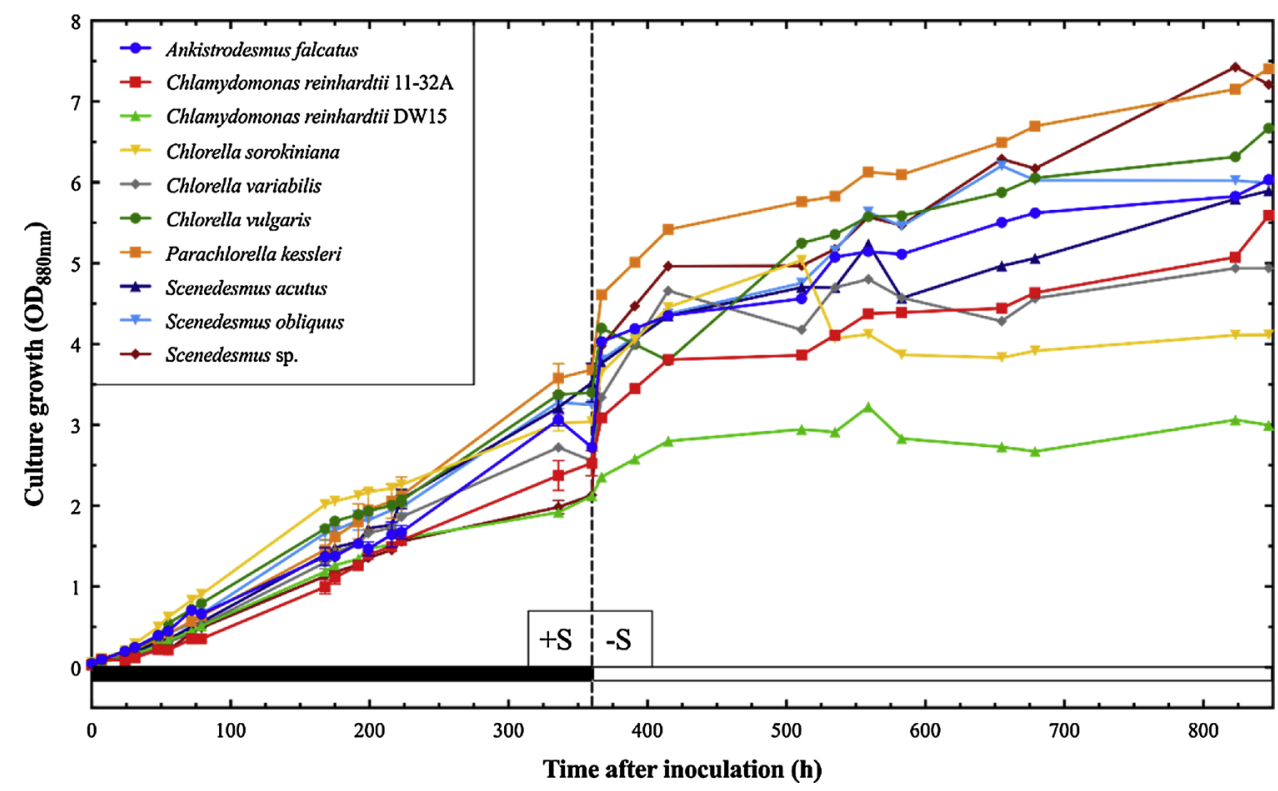

Fig. 2. Biomass growth, as determined by optical density, in sulfur-replete (dark bar), then sulfur depleted (white bar) medium for the ten microalgae strains. 


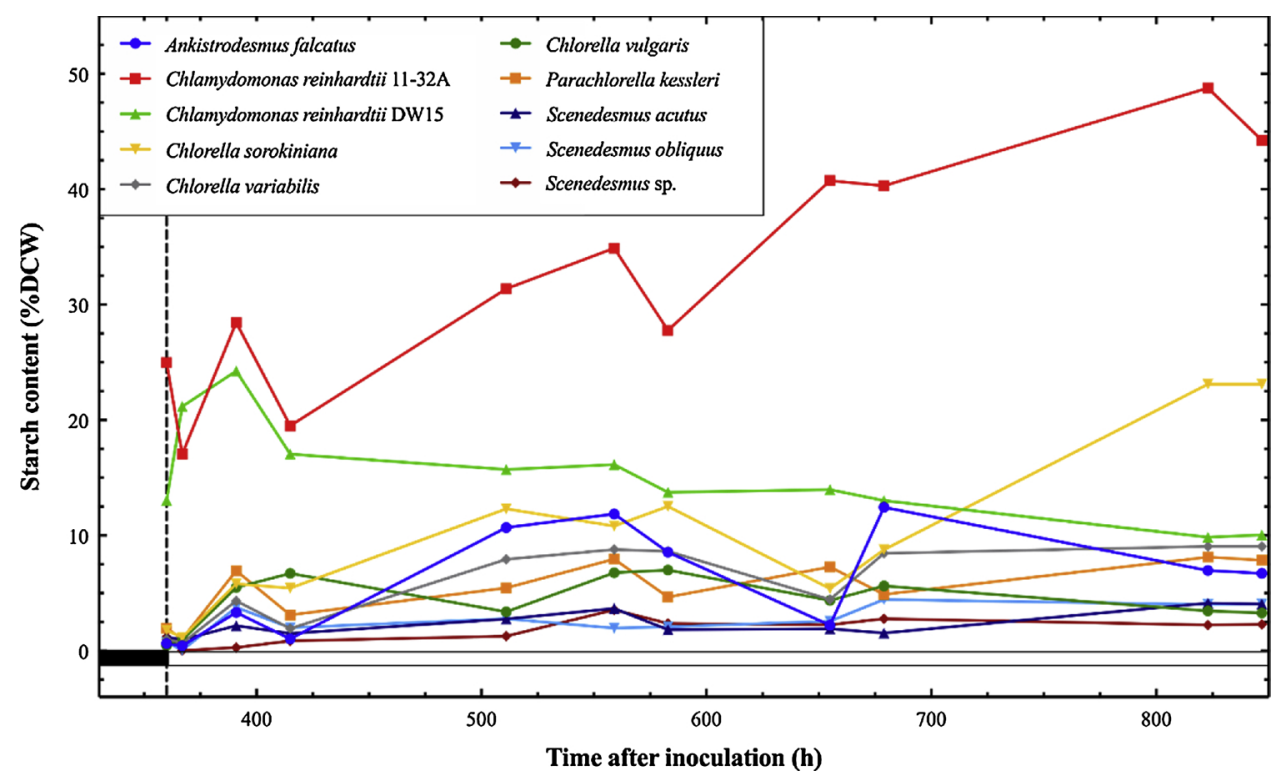

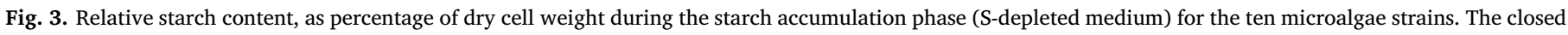
black bar marks a sulfur-replete medium, the white bar marks a sulfur-depleted medium.

decrease of C. reinhardtii 11-32A in favour of another homogenous Chlorella-like cell type. This faster-growing strain took place despite chemical sterilization (of both the reactor and the culture medium) prior inoculation and meticulous monitoring of the culture, highlighting the difficulty of upscaling microalgae cultures. Such contamination has not been observed for the 'non-accumulated' biomass.

The switch to a sulfur-less medium was performed at the 10th day $(258 \mathrm{~h})$. Cells were harvested after $480 \mathrm{~h}$ of culture, at a $3.715 \pm 0010 \mathrm{~g} / \mathrm{L}$ biomass concentration $\left(\mathrm{OD}_{880}=4.39\right)$. C. reinhardtii 11-32A then ended up representing rougly $30 \%$ of total cells, as determined by optical microscopy observations. This harvested biomass (named 'accumulated' biomass) was sent for an osidic analysis, as well as the one of a previous batch of $C$. reinhardtii 11-32A which did not undergo any nutrient stress and was harvested at middle-exponential phase of a fed-batch strategy (named 'non-accumulated' biomass). Osidic compositions of the two batches are reported in Table 1.

The composition of the 'non-accumulated' batch illustrates the very basal starch level in the species $C$. reinhardtii 11-32A. Being harvested at mid-exponential phase (dynamic equilibrium reached in a fed-batch system), the cells were at their full growth capacity, with a metabolism hardly storing any reserves. The 'accumulated' batch comprises about a third of $C$. reinhardtii 11-32A whose starch accumulation ability under sulfur depletion has already been proven by the screening experiments. Relative starch level in the harvested 'accumulated' biomass is however somewhat disappointing and most probably imputable to the contamination with Chlorella-like cells which did not respond as well to sulfur deprivation. If we consider that only C. reinhardtii 11-32A (representing about a third of the harvested biomass) responded to sulfur deprivation, this starch content within this cell-type reached about $54 \%$ $\mathrm{w} / \mathrm{w}$, which is consistent with previous results from the screening phase ( $49 \% \mathrm{w} / \mathrm{w}$ of starch after 20 days of sulfur-deprivation).

\subsection{Plasticization of microalgae}

Few works have shown that raw or waste biomass of microalgae could be plasticized and eventually blended with thermoplastic matrices. Protein-rich microalgae, i.e. Spirulina and Chlorella, were plasticized by thermocompression at $150^{\circ} \mathrm{C}$ and 24 bars with glycerol as plasticizer (Zeller, Hunt, Jones, \& Sharma, 2013). The authors found

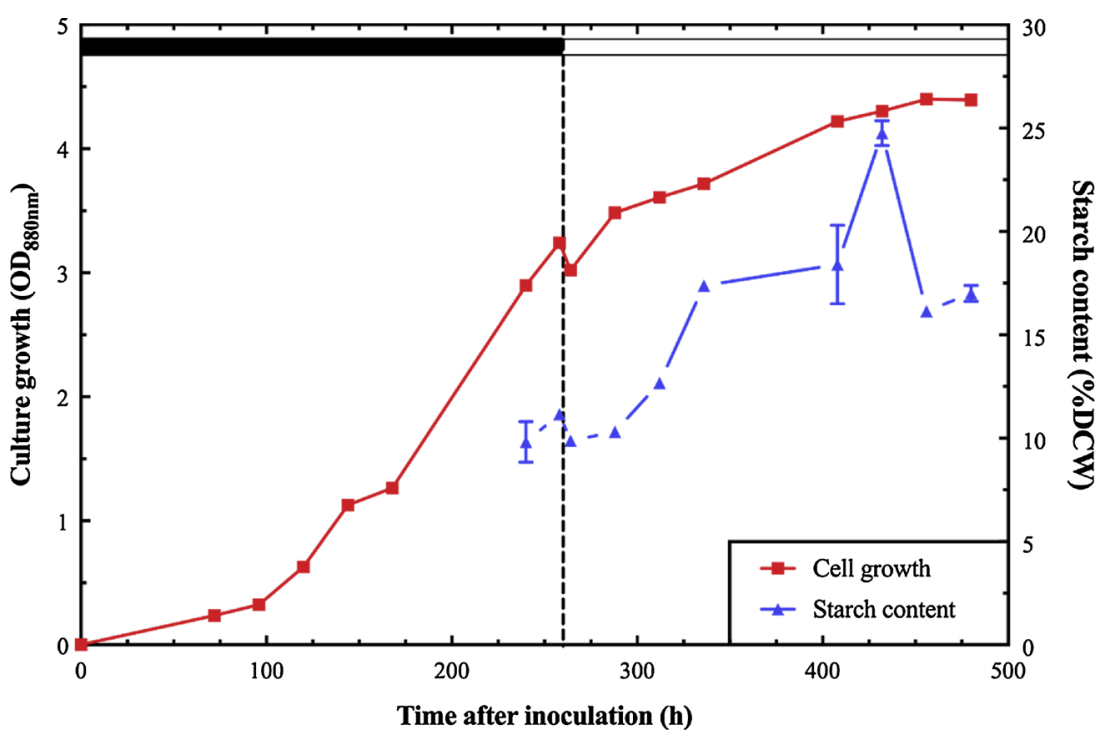

Fig. 4. Biomass growth, as determined by optical density (squares), and evolution of intracellular starch content (triangles) in sulfur-replete (dark bar), then sulfur depleted (white bar) medium for $C$. reinhardtii 11-32A in the $30 \mathrm{~L}$ PBR. 3 technical replicates were taken from the photobioreactor for each starch content determination. 
Table 1



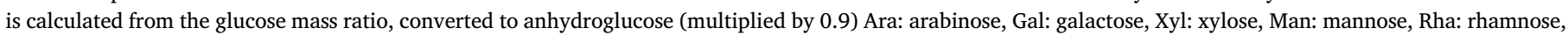
Glc: glucose.

\begin{tabular}{|c|c|c|c|c|c|c|c|}
\hline $\begin{array}{l}\text { Biomass } \\
\text { C. reinhardtii 11-32A }\end{array}$ & Ara $(\% w / w)$ & $\mathrm{Gal}(\% \mathrm{w} / \mathrm{w})$ & $\mathrm{Xyl}(\% \mathrm{w} / \mathrm{w})$ & $\operatorname{Man}(\% \mathrm{w} / \mathrm{w})$ & Rha $(\% w / w)$ & Glc $(\% w / w)$ & Relative starch content $(\% \mathrm{w} / \mathrm{w})$ \\
\hline 'Non-accumulated' & $1.04 \pm 0.37$ & $1.82 \pm 0.40$ & $0.31 \pm 0.2$ & $0.52 \pm 0.11$ & $0.39 \pm 0.05$ & $1.41 \pm 0.22$ & $1.27 \%$ \\
\hline 'Accumulated' & $0.4 \pm 0.03$ & $4.85 \pm 0.77$ & $1.04 \pm 0.06$ & $0.41 \pm 0.02$ & $4.26 \pm 0.41$ & $19.87 \pm 0.22$ & $17.82 \%$ \\
\hline
\end{tabular}

that a microalgae/glycerol ratio of 4:1 was the best compromise for an efficient plasticization and good thermomechanical properties of the molded specimens. However, no shearing was applied for mixing and plasticizing microalgae with glycerol. Failure surface observations of the specimens revealed heterogeneous microstructure with rough surfaces, suggesting an inefficient plasticization. Torres et al. (2015) investigated the plasticization of Nannochloropsis gaditana that was submitted to a prior transesterification process to produce biodiesel. The transesterification process resulted in a residual microalgae biomass (RMB) rich in protein that was further plasticized in an extruder at $100{ }^{\circ} \mathrm{C}$ with various amounts of glycerol, water and urea. Plasticized $\mathrm{RMB}$ was further mixed with poly(butylene adipate-co-terephthalate) PBAT and the authors found that the best PBAT/RMB composites in terms of RMB dispersion and mechanical properties were obtained for plasticization of RMB with $30 \%$ glycerol, $10 \mathrm{phr}$ of water and $7.5 \mathrm{phr}$ of urea. Based on these studies, the control of the plasticization process appears as a key issue for the use of microalgae in bioplastic formulations.

In this study, plasticization capacity of 'accumulated' $C$. reinhardtii 11-32A biomass was firstly investigated under static conditions, i.e. no shearing applied. A few cells were placed in large excess of glycerol and heated up to $140^{\circ} \mathrm{C}$ with a heating stage while observing it by optical microscopy. Same experimental protocol was followed with maize starch granules as reference. As seen in Video 1 (Supplementary material), maize starch granules start to swell at roughly $80^{\circ} \mathrm{C}$ and undergo large swelling above $120^{\circ} \mathrm{C}$ to reach a swelling ratio (ratio of final to initial diameter) of about $220 \%$, highlighting the well-known good plasticization capacity of glycerol towards pure starch granules. In contrast, with the 'accumulated' biomass, nearly no swelling of the small microalgae cells (individual cell or agglomerates) was observed even at $140{ }^{\circ} \mathrm{C}$ (Video 2 in Supplementary material). This illustrates very well the requirement for the disruption of microalgae cell walls prior any further biorefining process that seeks the access to intracellular components. As reviewed by Günerken et al. (2015), microalgae cell disruption could be envisaged by bead milling, high pressure homogenization, high speed homogenization, ultrasonication, microwave treatment, pulsed electric field treatment or non-mechanical methods and emerging biotechnologies such as enzymatic treatments. Yet, although it is highly expected for an efficient biorefinery process, the challenge of reliably breaking-up of microalgae cells holds. Besides, even if pure starch granules can swell substantially upon heating in the presence of an appropriate plasticizer (glycerol, sorbitol...), the specific mechanical energy brought by shearing forces in thermoplastic-processing tools such as extruders, was shown to be essential for the defragmentation and homogenous plasticization of pure starch granules (Barron, Bouchet, Della Valle, Gallant, \& Planchot, 2001; Barron, Della Valle, Colonna, \& Vergnes, 2002).

Based on these observations, the possibility to break-up and directly plasticize microalgae cells with glycerol was evaluated by continuous mechanical mixing in a lab-scale twin-screw extruder. Three batches of 'non-accumulated' $C$. reinhardtii 11-32A biomass were extruded with $30 \% \mathrm{w} / \mathrm{w}$ glycerol at extrusion temperatures of 100,120 and $150^{\circ} \mathrm{C}$, respectively, and observed using a binocular magnifier (Fig. 5A-C). At $150^{\circ} \mathrm{C}$, the extrudates are visibly darkened, suggesting that the biomass was degraded during the extrusion process (Fig. 5C). Cross-sectional profiles display a coarse structure with unplasticized material and visible cell wall fragments. The best processing temperature, limiting degradation and promoting regular flowing of the extrudate, was found at $120^{\circ} \mathrm{C}$ and selected for the plasticization of the 'accumulated' $C$. reinhardtii $11-32 \mathrm{~A}$ biomass with $30 \% \mathrm{w} / \mathrm{w}$ glycerol. As seen in Fig. 5D, a homogeneous plasticized macrostructure with no visible cell fragments was obtained, highlighting the positive effect of starch accumulation on the plasticization capacity of microalgae.

Microstructure of extruded 'non-accumulated' and 'accumulated' $C$. reinhardtii 11-32A was further investigated at higher magnification by SEM on cryo-fractured surfaces of extrudates. As seen in Fig. 6, a much more homogeneous microstructure was obtained with the 'accumulated' biomass with a smoother surface as compared to the irregular and fractured surface obtained with the 'non-accumulated' biomass (Fig. 6a and $\mathrm{d}$, respectively). Zooming within the extrudates microstructure shows agglomerated cells fragments in the case of the "non-accumulated' biomass (Fig. 6c) whereas a continuous phase with some dispersed-round shape particles of about $3-5 \mu \mathrm{m}$ is observed with the 'accumulated' biomass (Fig. 6e and f). This clearly evidences that starch accumulation in microalgae allows the partial plasticization of cells with glycerol provided that sufficient shearing, brought by the extrusion process, is applied. We assume that the round-shape particles observed in the 'accumulated' biomass are unbroken cells related to the aforementioned contamination with Chlorella-like cells (typical cell size of $2-10 \mu \mathrm{m}$ according to Havlik et al., 2013 and VanderGheynst, Guo, Cheng, \& Scher, 2013). These Chlorella-like cells with both a low amount of starch and more robust cell walls undergone limited disruption and plasticization during extrusion.

Based on our observations, both the capacity of intracellular biopolymers accumulation and the structural features of microalgae cells appear as two key criteria in the selection of relevant microalgae strains for an efficient plasticization for making bioplastics.

Thermal analysis by DSC was conducted to determine the glass transition temperature ( $\mathrm{Tg}$ ) of the resulting plasticized microalgae. Two successive heating scans (from $-50^{\circ} \mathrm{C}$ to $150{ }^{\circ} \mathrm{C}$ ) were applied to study the potential effect of drying on the glass transition. No water crystallization or fusion peaks were detected on the thermograms for both 'non-accumulated' and 'accumulated' biomass. Interestingly, only the 'accumulated' biomass showed a heat capacity variation related to glass transition of starch, confirming that starch plasticization with glycerol occurred during extrusion for this biomass. Values of $\mathrm{Tg}$ and heat capacity $(C p)$ variation are reported in Table 2. Pure starch/glycerol systems conditioned at equilibrium at $50 \%$ relative humidity $(\mathrm{RH})$ usually contain high amount of water due to their hydrophilicity, and exhibit two $\mathrm{Tg}$, e.g. $-21{ }^{\circ} \mathrm{C}$ for maize starch with $20 \%$ water $/ 25 \%$ glycerol and $80^{\circ} \mathrm{C}$ when dried (Sankri et al., 2010). For the 'accumulated' and plasticized microalgae, $\mathrm{Tg}$ is roughly $1.8^{\circ} \mathrm{C}$, higher than pure starch/glycerol systems probably due to the low amount of water within the system, i.e. $2.34 \%$ (Table 2). However, no significant shift of the $\operatorname{Tg}\left(1.6^{\circ} \mathrm{C}\right)$ was observed on the second heating run. The glass transition of plasticized microalgae thus appears to be fully reversible without any effect of drying after one heating cycle at $150^{\circ} \mathrm{C}$.

Finally, it should be pointed out that not only starch but also others polysaccharides and macromolecules (as proteins) present in the microalgae cells could be involved in the plasticization process and have 

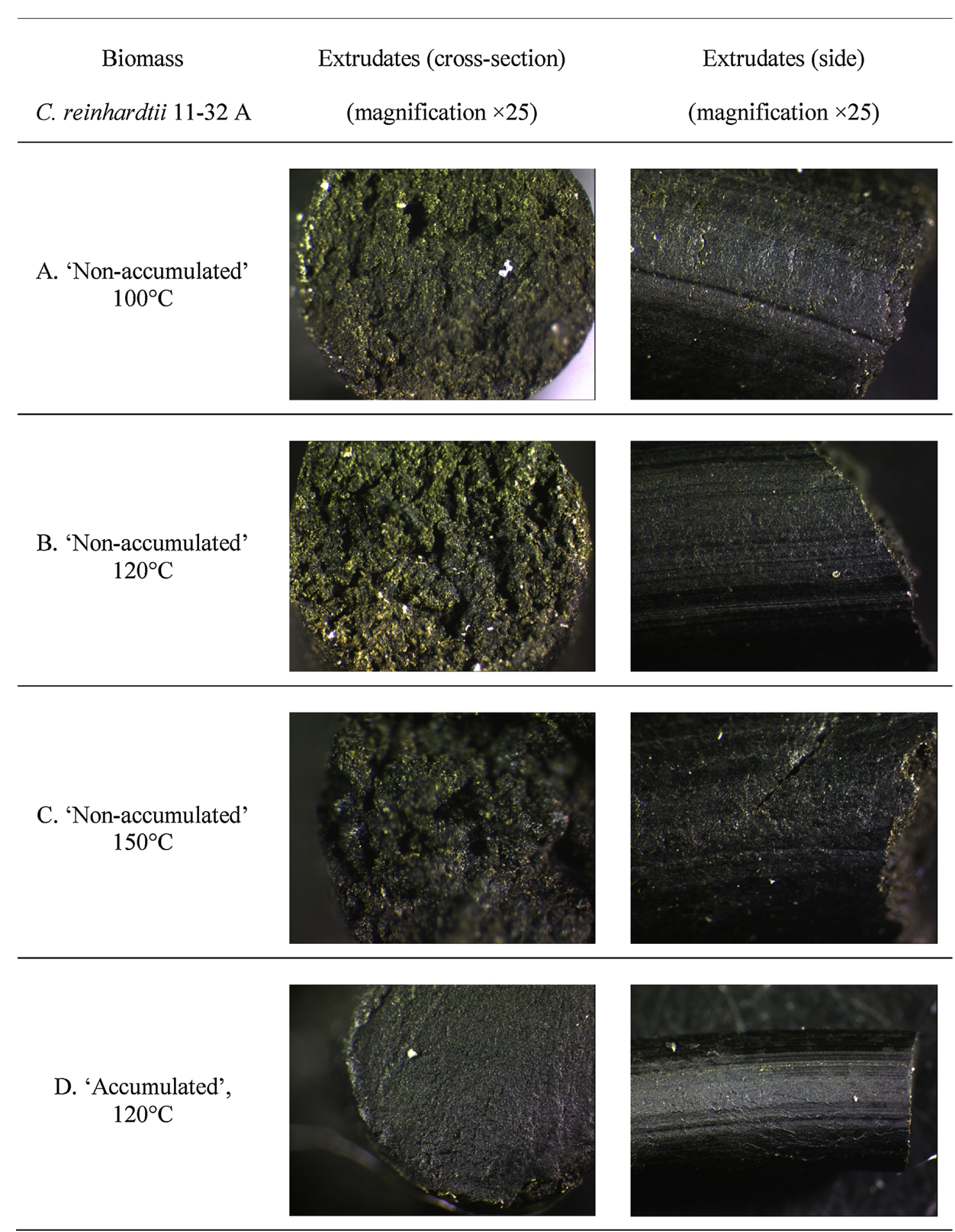

Fig. 5. Macroscopic structure of extrudates of extruded C. reinhardtii 11-32A: 'non-accumulated' (A-C) and 'accumulated' (D) biomasses observed under binocular microscope with PC acquisition. Both biomass were extruded using $30 \% \mathrm{w} / \mathrm{w}$ glycerol as a plasticizer and mixed at $100 \mathrm{rpm}$ during 2 min glycerol at extrusion temperatures of 100,120 and $150^{\circ} \mathrm{C}$.

an influence on the microstructure and thermal behavior of the plasticized microalgae. In this regard, future works will be focused on a better understanding of the effect of the overall composition of different strains, in particular variations in protein/starch ratio.

\section{Discussion and perspectives}

This study is a first step for the development of starch-based bioplastics from microalgae, intended at giving the definition of suitable biotechnological and processing routes. However, many opportunities for improvement can be considered for future developments.

Improving the production of starch by microalgae can be made by the selection of highly starch-producing microalgae strains and by optimizing the culture conditions for starch production. This screening methodology could be inspired by already existing protocol dedicated to lipid producing strains such as the one developed by Taleb et al. (2016). Considering non-food applicative prospects for microalgae based materials, one could see the use of genetically modified strains as 

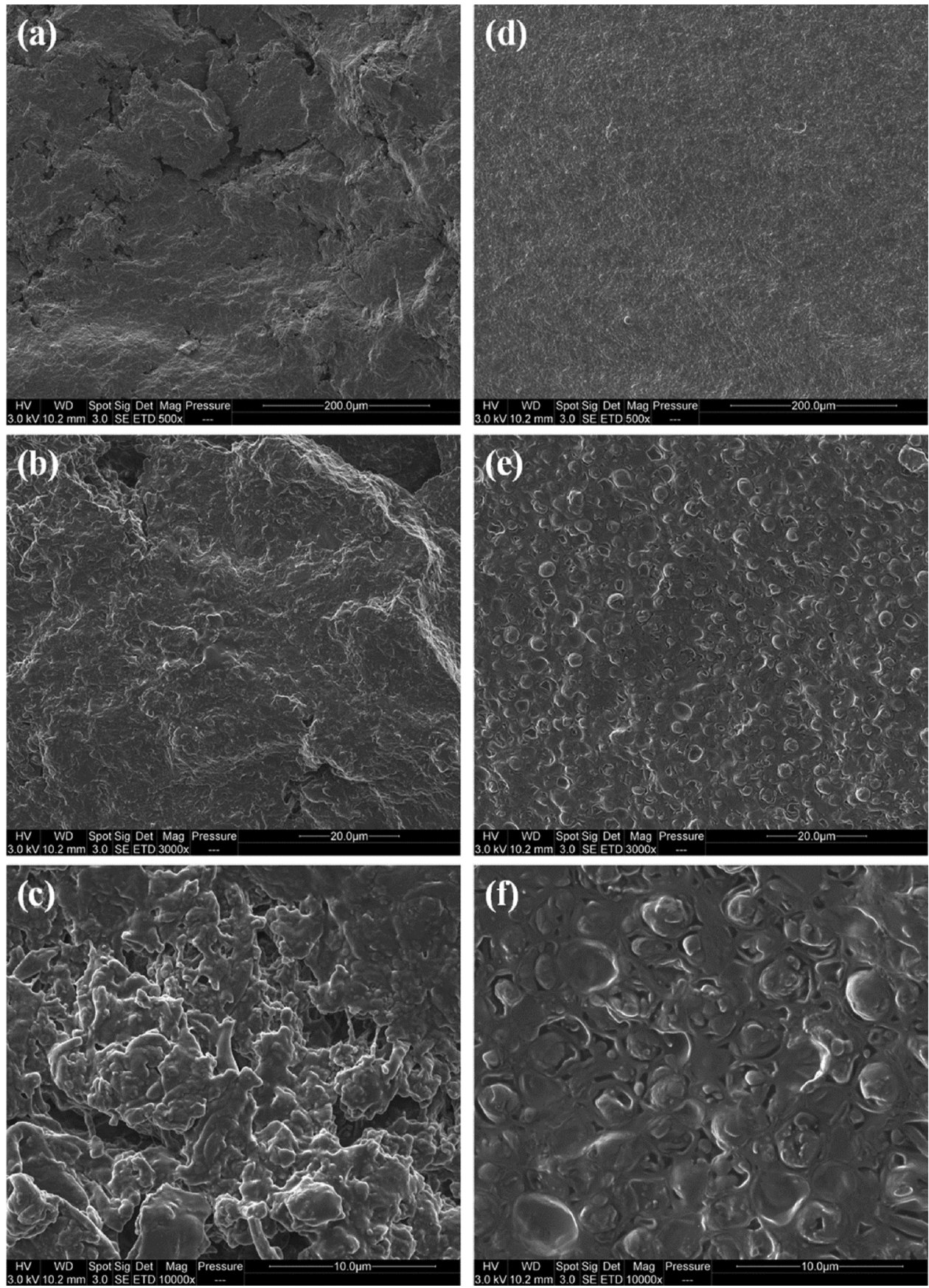

Fig. 6. SEM observations of cryo-fractured extrudates of extruded C. reinhardtii 11-32A: 'non-accumulated' (a-c) and 'accumulated' (e-g). Both biomasses were extruded using $30 \% \mathrm{w} / \mathrm{w}$ glycerol as a plasticizer and mixed at $120^{\circ} \mathrm{C}, 100 \mathrm{rpm}$ during $2 \mathrm{~min}$.

a promising perspective for future studies. Multiple $C$. reinhardtii mutants altered in their carbohydrate metabolism have been characterized, with two objectives: increase the overall intracellular starch content (Smith, 2008), and tailor its structure and quality, through the control of the amylose/amylopectine ratio (Delrue et al., 1992;
Zabawinski et al., 2001). Starch production is also influenced by many parameters such as $\mathrm{CO}_{2}$ concentration (Izumo et al., 2007), temperature (Nakamura \& Miyachi, 1982), light intensity (Brányiková et al., 2011). Medium composition, culture conditions and strategy (batch/fedbatch/continuous) should be optimized in order to maximize starch

Table 2

Glass transition temperatures $(\mathrm{Tg})$ determined by DSC as the onset of heat capacity variation for the two heating scans, and water content determined by TGA for 'non-accumulated' and 'accumulated' biomass.

\begin{tabular}{|c|c|c|c|c|c|}
\hline $\begin{array}{l}\text { Biomass } \\
\text { C. reinhardtii 11-32A }\end{array}$ & $\begin{array}{l}\mathrm{Tg}\left({ }^{\circ} \mathrm{C}\right) \\
\text { first heating run }\end{array}$ & $\begin{array}{l}\operatorname{Tg}\left({ }^{\circ} \mathrm{C}\right) \\
\text { second heating run }\end{array}$ & $\begin{array}{l}\mathrm{Cp}\left(\mathrm{J} / \mathrm{g} \cdot{ }^{\circ} \mathrm{C}\right) \\
\text { first heating run }\end{array}$ & $\begin{array}{l}C p\left(\mathrm{~J} / \mathrm{g} .{ }^{\circ} \mathrm{C}\right) \\
\text { second heating run }\end{array}$ & $\begin{array}{l}\text { Water content } \\
(\mathrm{wt} \%)\end{array}$ \\
\hline 'non-accumulated' & - & - & - & - & $1.75 \pm 0.1$ \\
\hline 'accumulated' & $1.79 \pm 0.47$ & $1.59 \pm 0.55$ & $0.206 \pm 0.02$ & $0.202 \pm 0.02$ & $2.34 \pm 0.2$ \\
\hline
\end{tabular}


productivity.

Limiting both the energy input and the number of steps required in these bioprocesses has long been identified a s a bottleneck for their economic relevance. Different crop strategies than the strict two-stage cultivation should be envisaged. The need for a complete biomass harvest to proceed to the medium switch is difficult to transfer to the large-scale and eventually hinders the cost-efficiency of the process, when considering the additional energy input required. An in-depth understanding and modelling of nutrient uptake dynamics would allow leaving the cells with a precise (limited) initial amount of nutrients, so that the auto-consumption of a particular macronutrient, along with culture growth, would suffice to auto-induce the ta rgeted stress condition, at a precise moment.

Furthermore, easing the access of the plasticizers and its mixing with the polysaccharides and other biopolymers appear as a cornerstone for a homogeneous plasticization. Melt processing of starch-enriched microalgal biomass can be improved by the screening of pretreatments methods to disrupt cell walls (Günerken et al., 2015) before extrusion. The pre-treatment technique will have to be specific to the chosen cell-type and non-degrading for the biopolymer chains. Our study notably shown that cells with a high cell volume / cell wall thickness ratio are easily lysed through sonication and autoclaving (starch titration protocol), but cells residues can remain after the plasticization if the biomass is not pre-fractioned. This supports the need of a pre-treatment step, regardless the cells robustness. Other plasticizers, polyols but also ionic liquids (Sankri et al., 2010) and blending with other biopolymers (e.g. biopolyesters) could also be considered to improve the plasticization process and the resulting functional properties of microalgae based bioplastics.

Finally, apart from its interests in the crafting of novel bioplastic materials, the stakes of starch production in microalgae also include the production of bioethanol by fermentation of this microalgal starch (Ho et al., 2013). In the objective of bioethanol production, a few studies have already proved the potential to take advantage of the metabolic flexibility of microalgae in d esigning s imple bioprocesses comprising successively both starch storage and its fermentation into ethanol (Hirano et al., 1997). In this regard, developing starch production strategy from microalgae could benefit $\mathrm{t} \mathrm{o} \mathrm{b}$ oth $\mathrm{t}$ he $\mathrm{b}$ ioplastic and bioethanol industries.

\section{Conclusion}

This study successfully provided a proof-of-concept for the production of starch-based bioplastics from microalgae. C. reinhardtii 11$32 \mathrm{~A}$ was found to be a satisfactory starch producing microalgae strain with up to $49 \% \mathrm{w} / \mathrm{w}$ of starch and a maximum biomass productivity of $5.07 \mathrm{~g} / \mathrm{L}$ obtained in flasks. Starch enriched $C$. reinhardtii 11-32A biomass was successfully produced in a $30 \mathrm{~L}$ PBR highlighting the feasibility of up-scaling microalgae starch to industrial production. This starch-rich microalgal biomass was then found to show interesting plasticization capacity in a twin-screw extruder operated at $120^{\circ} \mathrm{C}$, especially when compared to a non-accumulated biomass. These results open perspectives for the development of starch-based bioplastics from microalgae as a new platform and tailored biomass resource.

\section{Acknowledgments}

This work was supported by the program CARNOT AVENE PME and by the LabEx CheMISyst (funding from The French National Research Agency under the program "Investissements d'Avenir", reference ANR10-LabX-05-01).

\section{Appendix A. Supplementary data}

Supplementary material related to this article can be found, in the online version, at doi:https://doi.org/10.1016/j.carbpol.2018.12.057.

\section{References}

Ball, S. G., Dirick, L., Decq, A., Martiat, J. C., \& Matagne, R. F. (1990). Physiology of starch storage in the monocellular alga Chlamydomonas reinhardtii. Plant Science, $66,1-9$.

Barron, C., Bouchet, B., Della Valle, G., Gallant, D. J., \& Planchot, V. (2001). Microscopical study of the destructuring of waxy maize and smooth pea starches by shear and heat at low hydration. Journal of Cereal Science, 33, 289-300.

Barron, C., Della Valle, G., Colonna, P., \& Vergnes, B. (2002). Energy balance of low hydrated starches transition under shear. Journal of Food Science, 67, 1426-1437.

Blankenship, R. E. (1992). Origin and early evolution of photosynthesis. Photosynthesis Research, 33, 91-111.

Brányiková, I., Maršálková, B., Doucha, J., Brányik, T., Bišová, K., Zachleder, V., et al. (2011). Microalgae-novel highly efficient starch producers. Biotechnology and Bioengineering, 108, 766-776.

Buléon, A., Gallant, D.-J., Bouchet, B., Mouille, G., D’Hulst, C., Kossman, J., et al. (1997). Starches from A to C (Chlamydomonas reinhardtii as a model microbial system to investigate the biosynthesis of the plant amylopectin crystal). Plant Physiology, 115, 949-957.

Chen, M., Tang, H., Ma, H., Holland, T. C., Ng, K. Y. S., \& Salley, S. O. (2011). Effect of nutrients on growth and lipid accumulation in the green algae Dunaliella tertiolecta. Bioresource Technology, 102, 1649-1655.

Cheng, Y. S., Labavitch, J. M., \& VanderGheynst, J. S. (2014). Elevated CO 2 concentration impacts cell wall polysaccharide composition of green microalgae of the genus Chlorella. Letters in Applied Microbiology, 60, 1-7.

Chochois, V., Dauvillée, D., Beyly, A., Tolleter, D., Cuiné, S., Timpano, H., et al. (2009) Hydrogen production in Chlamydomonas: Photosystem II-dependent and -independent pathways differ in their requirement for starch metabolism. Plant Physiology, 151, 631-640.

Delrue, B., Fontaine, T., Routier, F., Decq, A., Wieruszeski, J. M., Van Den Koornhuyse, N., et al. (1992). Waxy Chlamydomonas reinhardtii: monocellular algal mutants defective in amylose biosynthesis and granule-bound starch synthase activity accumulate a structurally modified amylopectin. Journal of Bacteriology, 174, 3612-3620.

Delrue, F., Álvarez-Díaz, P. D., Fon-Sing, S., Fleury, G., \& Sassi, J.-F. (2016). The environmental biorefinery: Using microalgae to remediate wastewater, a win-win paradigm. Energies, 132.

Dragone, G., Fernandes, B. D., Abreu, A. P., Vicente, A. A., \& Teixeira, J. A. (2011) Nutrient limitation as a strategy for increasing starch accumulation in microalgae. Applied Energy, 88, 3331-3335.

Dubois, M., Gilles, K. A., Hamilton, J. K., Rebers, P. A., \& Smith, F. (1956). Colorimetric method for determination of sugars and related substances. Analytical Chemistry, 28, 350-356.

González-Ballester, D., Casero, D., Cokus, S., Pellegrini, M., Merchant, S. S., \& Grossman, A. R. (2010). RNA-seq analysis of sulfur-deprived Chlamydomonas cells reveals aspects of acclimation critical for cell survival. The Plant Cell, 22, 2058-2084.

Günerken, E., D’Hondt, E., Eppink, M. H. M., Garcia-Gonzalez, L., Elst, K., \& Wijffels, R. H. (2015). Cell disruption for microalgae biorefineries. Biotechnology Advances, 33, 243-260.

Halley, P. J., \& Dorgan, J. R. (2011). Next-generation biopolymers: Advanced functionality and improved sustainability. MRS Bulletin, 36, 687-691.

Havlik, I., Reardon, K. F., Ünal, M., Lindner, P., Prediger, A., Babitzky, A., et al. (2013). Monitoring of microalgal cultivations with on-line, flow-through microscopy. Algal Research, 2(3), 253-257.

Hirano, A., Ueda, R., Hirayama, S., \& Ogushi, Y. (1997). $\mathrm{CO}_{2}$ fixation and ethanol production with microalgal photosynthesis and intracellular anaerobic fermentation. Eneroy, 22, 137-142.

Ho, S.-H., Huang, S.-W., Chen, C.-Y., Hasunuma, T., Kondo, A., \& Chang, J.-S. (2013). Bioethanol production using carbohydrate-rich microalgae biomass as feedstock. Bioresource Technology, 135, 191-198.

Hu, Q., Sommerfeld, M., Jarvis, E., Ghirardi, M., Posewitz, M., Seibert, M., et al. (2008). Microalgal triacylglycerols as feedstocks for biofuel production: Perspectives and advances. The Plant Journal, 54, 621-639.

Hutner, S. H., Provasoli, L., Schatz, A., \& Haskins, C. P. (1950). Some approaches to the study of the role of metals in the metabolism of microorganisms. Proceedings of the American Philosophical Society, 94, 152-170.

Izumo, A., Fujiwara, S., Oyama, Y., Satoh, A., Fujita, N., Nakamura, Y., et al. (2007)، Physicochemical properties of starch in Chlorella change depending on the $\mathrm{CO}_{2}$ concentration during growth: Comparison of structure and properties of pyrenoid and stroma starch. Plant Science, 172, 1138-1147.

Jaiswal, S., \& Chibbar, R. N. (2017). Amylopectin small chain glucans form structure fingerprint that determines botanical origin of starch. Carbohydrate Polymers, 158, $112-123$.

Jerez, C. G., Malapascua, J. R., Sergejevová, M., Figueroa, F. L., \& Masojídek, J. (2015). Effect of nutrient starvation under high irradiance on lipid and starch accumulation in Chlorella fusca(Chlorophyta). Marine Biotechnology, 18, 24-36.

Johnson, X., \& Alric, J. (2013). Central carbon metabolism and electron transport in Chlamydomonas reinhardtii, metabolic constraints for carbon partitioning between oil and starch. Eukaryotic Cell, 12, 776-793.

Kamerling, J. P., Gerwig, G. J., Vliegenthart, J. F., \& Clamp, J. R. (1975). Characterization by gas-liquid chromatography-mass spectrometry and proton-magnetic-resonance spectroscopy of pertrimethylsilyl methyl glycosides obtained in the methanolysis of glycoproteins and glycopeptides. The Biochemical Journal, 151(3), 491-495.

Kobayashi, M., Kurimura, Y., \& Tsuji, Y. (1997). Light-independent, astaxanthin production by the green microalga Haematococcus pluvialis under salt stress. Biotechnology Letters, 19, 507-509. 
Li, Y., Horsman, M., Wang, B., Wu, N., \& Lan, C. Q. (2008). Effects of nitrogen sources on cell growth and lipid accumulation of green alga Neochloris oleoabundans. Applied Microbiology and Biotechnology, 81, 629-636.

Ma, X., \& Yu, J. (2004). The plasticizers containing amide groups for thermoplastic starch. Carbohydrate Polymers, 57, 197-203.

Markou, G., Angelidaki, I., \& Georgakakis, D. (2012). Microalgal carbohydrates: An overview of the factors influencing carbohydrates production, and of main bioconversion technologies for production of biofuels. Applied Microbiology and Biotechnology, 96, 631-645.

Montreuil, J., Bouquelet, S., Debray, H., Fournet, B., Spik, G., \& Strecker, G. (1986), Glycoproteins. In M. F. Chaplin, \& J. K. Kennedy (Eds.). Carbohydrates analysis: A practical approach (pp. 143-204). Oxford: IRL press.

Mülhaupt, R. (2013). Green polymer chemistry and bio-based plastics: Dreams and reality. Macromolecular Chemistry and Physics, 214, 159-174.

Nakamura, Y., \& Miyachi, S. (1982). Effect of temperature on starch degradation in Chlorella vulgaris 11 h cells. Plant \& Cell Physiology, 23, 333-341.

Norton, T. A., Melkonian, M., \& Andersen, R. A. (1996). Algal biodiversity. Phycologia, 35 , 308-326.

Nyilasy, G., Gangadharbatla, H., \& Paladino, A. (2014). Perceived greenwashing: The interactive effects of green advertising and corporate environmental performance on consumer reactions. Journal of Business Ethics, 125, 693-707.

Radakovits, R., Jinkerson, R. E., Darzins, A., \& Posewitz, M. C. (2010). Genetic engineering of algae for enhanced biofuel production. Eukaryotic Cell, 9, 486-501.

Ren, X. (2003). Biodegradable plastics: A solution or a challenge? Journal of Cleaner Production, 11, 27-40.

Sankri, A., Arhaliass, A., Dez, I., Gaumont, A. C., Grohens, Y., Lourdin, D., et al. (2010). Thermoplastic starch plasticized by an ionic liquid. Carbohydrate Polymers, 82(2), 256-263. https://doi.org/10.1016/j.carbpol.2010.04.032.

Schmollinger, S., Mühlhaus, T., Boyle, N. R., Blaby, I. K., Casero, D., Mettler, T., et al. (2014). Nitrogen-sparing mechanisms in Chlamydomonas affect the transcriptome, the proteome, and photosynthetic metabolism. The Plant Cell, 26, 1410-1435.

Singh, J., \& Saxena, R. C. (2015). An introduction to microalgae: Diversity and significance. In S.-K. Kim (Ed.). Handbook of Marine microalgae: Biotechnology advances (pp. 11-24). Amsterdam: Academic Press.
Smith, A. M. (2008). Prospects for increasing starch and sucrose yields for bioethanol production. The Plant Journal for Cell and Molecular Biology, 54, 546-558.

Somani, B. L., Khanade, J., \& Sinha, R. (1987). A modified anthrone-sulfuric acid method for the determination of fructose in the presence of certain proteins. Analytical Biochemistry, 167, 327-330.

Swanson, C. L., Shogren, R. L., Fanta, G. F., \& Imam, S. H. (1993). Starch-plastic materials-Preparation, physical properties, and bio-degradability (a review of recent USDA research). Journal of Environmental Polymer Degradation, 1, 155-166.

Taleb, A., Kandilian, R., Touchard, R., Montalescot, V., Rinaldi, T., Taha, S., et al. (2016). Screening of freshwater and seawater microalgae strains in fully controlled photobioreactors for biodiesel production. Bioresource Technology, 218, 480-490.

Torres, S., Navia, R., Murdy, R. C., Cooke, P., Misra, M., \& Mohanty, A. K. (2015). Green composites from residual microalgae biomass and poly(butylene adipate-co-terephthalate): Processing and plasticization. ACS Sustainable Chemistry \& Engineering 3(4), 614-624.

VanderGheynst, J. S., Guo, H. Y., Cheng, Y. S., \& Scher, H. (2013). Microorganism viability influences internal phase droplet size changes during storage in water-in-oil emulsions. Bioprocess and Biosystems Engineering, 36(10), 1427-1434.

Vítová, M., Bišová, K., Kawano, S., \& Zachleder, V. (2015). Accumulation of energy reserves in algae: From cell cycles to biotechnological applications. Biotechnology Advances, 33, 1204-1218.

Wijffels, R. H., Kruse, O., \& Hellingwerf, K. J. (2013). Potential of industrial biotechnology with cyanobacteria and eukaryotic microalgae. Current Opinion in Biotechnology, 24, 405-413.

Yao, C., Ai, J., Cao, X., Xue, S., \& Zhang, W. (2012). Enhancing starch production of a marine green microalga Tetraselmis subcordiformis through nutrient limitation. Bioresource Technology, 118, 438-444.

Zabawinski, C., Van Den Koornhuyse, N., D’Hulst, C., Schlichting, R., Giersch, C., Delrue, B., et al. (2001). Starchless mutants of Chlamydomonas reinhardtii lack the small subunit of a heterotetrameric ADP-glucose pyrophosphorylase. Journal of Bacteriology, 183, 1069-1077.

Zeller, M. A., Hunt, R., Jones, A., \& Sharma, S. (2013). Bioplastics and their thermoplastic blends from Spirulina and Chlorella microalgae. Journal of Applied Polymer Science, 130, 3263-3275 